\title{
Persepsi Alumni Matematika Terhadap Layanan dan Fasilitas Akademik Serta Penelitian dan Pengabdian kepada Masyarakat Di Program Studi Matematika FMIPA UNSRAT dengan Menggunakan Analisis Korespondensi
}

\author{
${ }^{1}$ Yohana Pangemanan, ${ }^{2}$ Djoni Hatidja, ${ }^{3}$ Hanny A. H. Komalig \\ ${ }^{1}$ Program Studi Matematika, FMIPA, UNSRAT, yohana.pangemanan@yahoo.com \\ ${ }^{2}$ Program Studi Matematika, FMIPA, UNSRAT, dhatidja@yahoo.com \\ ${ }^{3}$ Program Studi Matematika, FMIPA, UNSRAT, hanny07@yahoo.com
}

\begin{abstract}
The research has been conducted to determine the perceptions of mathematics alumni about services and academic facilities also scientific publications, research, and community service in Mathematics Department Faculty of Natural Science Sam Ratulangi University Manado using Correspondence Analysis. The data used is primary data in the form of a questionnaire distributed to 50 alumni who graduate on 2006 until 2013 Mathematics Department UNSRAT Manado Correspondence Analysis result shows that the variable use of technology to assist the completion of administrative work majors have a good percentage of the most widely assessed by the percentage of alumni while most are judged to be good by the alumni of that programming courses with a SIM facility. For other categories were deemed good by alumni.
\end{abstract}

Keywords: correspondence analysis, alumni, service.

\begin{abstract}
Abstrak
Telah dilakukan penelitian untuk mengetahui bagaimana persepsi alu mni program studi matematika terhadap layanan dan fasilitas akademik serta publikasi ilmiah, riset, dan pengabdian pada masyarakat di program studi Matematika Faku ltas MIPA UNSRAT Manado dengan menggunakan Analisis Korespondensi. Data yang digunakan adalah data primer berupa kuesioner yang dibagikan kepada 50 alumni lulusan 20062013 Jurusan Matematika FMIPA UNSRAT Manado. Hasil Analisis Korespondensi diperoleh bahwa untuk variabel pemanfaatan teknologi untuk membantu penyelesaian pekerjaan administrasi jurusan memiliki presentase paling banyak dinilai baik oleh alumni sedangkan untuk presentase paling banyak yang dinilai tidak baik oleh alu mni yaitu pemrograman mata kuliah dengan fasilitas SIM. Secara umum untuk kategorikategori lainnya dinilai baik oleh alu mn i.
\end{abstract}

Kata kunci: ana lisis korespondensi, alu mni, pelayanan.

\section{Pendahuluan}

Keberhasilan sebuah institusi yang menghasilkan lulusannya adalah sejauh mana lulusannya dapat mengamalkan ilmu dalam bidangnya di masyarakat. Sumber daya manusia merupakan salah satu faktor penting untuk lebih meningkatkan suatu kualitas dalam pelayanan. Pelayanan adalah proses membantu orang lain dengan cara-cara tertentu dimana sensitivitas dan kemampuan interpersonal dibutuhkan untuk menciptakan kepuasan dan loyalitas yang ditentukan oleh keakraban, kehangatan, penghargaan, kedermawanan, dan kejujuran yang dilakukan oleh penyedia jasa.

Fakultas Matematika dan Ilmu Pengetahuan Alam UNSRAT merupakan fakultas yang bertujuan untuk mengembangkan pusat pendidikan dan pelatihan ilmu-ilmu Matematika dan Ilmu Pengetahuan Alam serta pusat penelitian dan pengembagnan konservasi SDA, hasil bahan alam, bioteknologi, pemanfaatan tenaga alam, serta komputasi dan informatika yang terkemuka di Kawasan Timur Indonesia dan diakui dunia Internasional. Untuk meningkatkan pelayanan maka perlu diperhatikan persepsi mahasiswa dalam hal ini dilihat dari pelayanan yang diterima selama menjadi mahasiswa. Analis is korespondensi merupakan salah satu teknik untuk melihat persepsi alumni tentang pelayanan.

Perumusan masalah dalam penelitian ini adalah bagaimana mendeskripsikan persespi alumni jurusan matematika terhadap layanan dan fasilitas akademik serta publikasi ilmiah, riset, dan pengabdian masyarakat di jurusan Matematika Fakultas MIPA Universitas Sam Ratulangi 
Manado dan bagaimana memetakan peta persepsi alumni jurusan matematika terhadap layanan dan fasilitas akademik serta publikasi ilmiah, riset, dan pengabdian masyarakat di jurusan Matematika Fakultas MIPA Universitas Sam Ratulangi Manado dengan menggunakan Analis is Korespondensi.

Tujuan dari penelitian ini adalah untuk mendeskripsikan persepsi alumni jurusan matematika FMIPA UNSRAT berdasarkan layanan dan fasilitas akademik serta publikasi ilmiah, riset, dan pengabdian masyarakat di jurusan Matematika FMIPA UNSRAT dan untuk mengetahui bagaimana cara mengolah data untuk mencari peta persepsi alumni matematika terhadap layanan dan fasilitas akademik serta publikasi ilmiah, riset, dan pengabdian masyarakat di jurusan Matematika Fakultas MIPA UNSRAT Manado dengan menggunakan Analisis Korespondensi.

\section{Analisis Korespondensi}

Analisis ini diartikan Sebagai teknik penyajian data antar baris, antar kolom, dan antara baris dan kolom dari tabel kontingensi (dua arah yang kemudian dapat diperluas untuk tabel kontingensi multi arah) pada suatu ruang vektor berdimensi kecil dan optimal [2] .

\subsection{Metode Dasar dan Algoritma Dasar Analis is Korespondensi}

Analisis korespondensi adalah suatu adaptasi data kategorik dari analisis komponen utama atau Principal Component Analysis (PCA) yang merupakan metode untuk mengidentifikasi dimensi untuk menjelaskan variansi maximum data metrik [2]. Kedua metode didasarkan pada dekomposisi dari matriks normal dan pusat, menggunakan salah satu dari dekomposisi nilai eigen dan vektor eigan dari matriks simetris persegi atau dekomposisi nilai singular atau Singular-Value Decomposition (SVD) pada matriks persegi [1].

Untuk menyatakan algoritma dasar dari analisis korespondensi, kita gunakan tabel silang atau kontingensi dari dua variabel dengan baris $I$ dan kolom $J$ yang dinotasikan sebagai $\mathrm{N}$, dengan elemen $n_{i j}$. Langkah pertama, matriks korespondensi P dihitung dengan elemen $p_{i j}=n_{i j} / n$, dimana $n$ jumlah total dari $\mathrm{N}$. Analisis korespondensi $\mathrm{P}$ tidak melibatkan ukuran sampel $n$ kecuali aspek statistika inferensia seperti selang kepercayaan. Untuk menghubungkan setiap elemen $p_{i j}$ dari matrik $\mathrm{P}$ adalah jumlah baris $p_{i=} n_{i} / n$ dan jumlah kolom $p_{j=} n_{j} / n$ yang dinotasikan dengan $r_{i}$ dan $c_{j}$ secara berturut-turut. Frekuensi relative marginal ini disebut massa, yang berfungsi untuk pemusatan dan normalisasi matriks korespondensi.

Dibawah hipotesis nol dari ketergantungan, nilai harapan dari frekuensi relarif $p_{i j}$ adalah hasil kali $r_{i} c_{j}$ dari massa. Pemusatan melibatkan perhitungan selisih $\left(p_{i j}-r_{i} c_{j}\right)$ antara frekuensi relatif harapan dan observasi, dan normalisasi yang melibatkan pembagian selisih dengan akar kuadrat dari ricjuntuk menghasilkan matriks sisa standarisasi $S_{i j}=\left(p_{i j}-r_{i} c_{j}\right) / V c_{i}$. Dalam notasi matriks dapat ditulis [1] :

$$
S=D_{r}^{-1 / 2}\left(\mathrm{P}-\mathrm{rc}^{\mathrm{T}}\right) D_{c}^{-1 / 2}
$$

dimana, $\mathrm{r}$ dan $\mathrm{c}$ adalah vekor-vektor baris dan kolom massa dan $\mathrm{D}_{r}$ dan $\mathrm{D}_{c}$ adalah matriks diagonal dengan massa-massa pada diagonal. Jumlah kuadrat elemen dari matriks sisa standarisasi $\sum_{i} \sum_{j} s_{i j}^{2}=$ trace $\left(\mathrm{SS}^{\mathrm{T}}\right)$, disebut total inersia dan merupakan jumlah kuantitas dari variansi dalam tabel silang. Karena sisa-sisa standarisasi pada S mirip dengan ini dalam kalkulasi statistik chi-square $\chi^{2}$, yang merupakan bagian dari $n$ untuk mengubah frekuensi asli ke relatif lainnya dengan hubungan sederhana berikut :

$$
\text { total inersia }=\chi^{2 / \mathrm{n}}
$$

Struktur asosiasi pada matriks $S$ ditemukan dengan menggunakan SVD yaitu :

$$
\mathrm{S}=\mathrm{U} \sum \mathrm{V}^{\mathrm{T}}
$$

dimana, $\sum$ adalah matriks diagonal dengan nilai-nilai singular dengan urutan menurun $\sigma_{1} \geq \sigma_{2} \geq \ldots$ $\sigma_{\mathrm{S}}<0$, dimana $\mathrm{S}$ adalah rank dari matriks $\mathrm{S}$. Kolom dari $\mathrm{U}$ disebut vektor singular kiri dan $\mathrm{V}$ disebut vektor singular kanan yang ortonormal yaitu $U^{\mathrm{T}} \mathrm{V}=\mathrm{V}^{\mathrm{T}} \mathrm{V}=\mathrm{I}$. Hubungan antara SVD dan dekomposisi nilai eigen dapat ditulis sebagai berikut [1] :

$$
\begin{aligned}
& \mathrm{STS}=\mathrm{V} \sum \mathrm{U}^{\mathrm{T}} \mathrm{U} \sum \mathrm{V}^{\mathrm{T}}=\mathrm{V} \sum^{2} \mathrm{~V}^{\mathrm{T}}=\mathrm{V} \Lambda \mathrm{V}^{\mathrm{T}} \\
& \mathrm{SS} \mathrm{S}^{\mathrm{T}}=\mathrm{U} \sum \mathrm{V}^{\mathrm{T}} \mathrm{V} \sum \mathrm{U}^{\mathrm{T}}=\mathrm{U} \sum^{2} \mathrm{U}^{\mathrm{T}}=\mathrm{U} \Lambda \mathrm{U}^{\mathrm{T}}
\end{aligned}
$$


Yang menunjukan bahwa vektor singular kanan dari S berkorespondensi dengan vektor eigen dari $\mathrm{S}^{\mathrm{T}} \mathrm{S}$, vektor singular kiri berkorespondensi dengan $\mathrm{SS}^{\mathrm{T}}$ dan nilai singular kuadrat $\sigma^{2}$ dalam $\sum^{2}$ berkorespondensi dengan nilai eigen $\lambda$ dari $\mathrm{S}^{\mathrm{T}} \mathrm{S}$ atau SS $\mathrm{SS}^{\mathrm{T}}$ dimana $\Lambda$ matriks diagonal nilai eigen. Dalam konteks analisis korespondensi, nilai-nilai eigen ini disebut inersia utama dan jumlahnya $\sum_{s} \lambda_{s}$ adalah sama dengan total inersia karena trace $\left(\mathrm{SS}^{\mathrm{T}}\right)=\operatorname{trace}\left(\mathrm{S}^{\mathrm{T}} \mathrm{S}\right)=\operatorname{trace}\left(\sum^{2}\right)=\operatorname{trace}(\Lambda)$.

SVD memberikan semua hasil yang dibuat untuk membuat koordinat standard dan utama yang dapat dihitung untuk kategori baris dan kolom :

$\begin{array}{lll}\text { baris koordinat utama } & : & \mathrm{F}=D_{r}^{-1 / 2} \mathrm{U} \sum \\ \text { baris koordinat standar } & : & \mathrm{A}=D_{r}^{-1 / 2} \mathrm{U} \\ \text { kolom koordinat utama } & : & \mathrm{G}=D_{c}^{-1 / 2} \mathrm{~V} \sum \\ \text { kolom koordinat standar } & : & \mathrm{B}=D_{c}^{-1 / 2} \mathrm{~V}\end{array}$

Untuk peta dimensi dua kita dapat menggunakan salah satu dari :

a. Koordinat kolom yang pertama dari matriks $F$ dan $G$ untuk peta simetris.

b. A dan $G$ untuk peta asimetris dari kolom.

c. F dan B untuk peta asimetris dari baris.

Proporsi inersia menjelaskan $\left(\sigma_{1}^{2}+\sigma_{2}^{2}\right) / \sum_{s} \sigma_{s}^{2},\left(\lambda_{1}+\lambda_{2}\right) / \sum_{s} \lambda_{s}[1]$.

\section{Metode Penelitian}

Penelitian ini menggunakan data primer melalui kuisoner yang berisi indikator-indikator persepsi layanan, fasilitas akademik, publikasi ilmiah, riset, dan pengabdian masyarakat yang diperoleh alumni jurusan matematika FMIPA UNSRAT. Kuisoner ini dibag ikan langsung kepada alumni Program Studi Matematika FMIPA UNSRAT, dibagikan melalui fasilitas e-mail untuk alumni yang berada di luar daerah dan juga melalui via telepon. Populasi yang dijadikan objek penelitian adalah alumni Program Studi Matematika FMIP A UNSRAT yang berjumlah 128 orang.

Variabel-variabel yang digunakan untuk mengukur sikap, pendapat, dan persepsi seseorang menggunakan tipe data skala Likert yang memungkinkan responden (alumni) menjawab pertanyaan atau mengekspresikan tingkat pendapat mereka dari setiap butir pertanyaan.

\section{Hasil Dan Pembahasan}

\subsection{Gambaran Umum Responden}

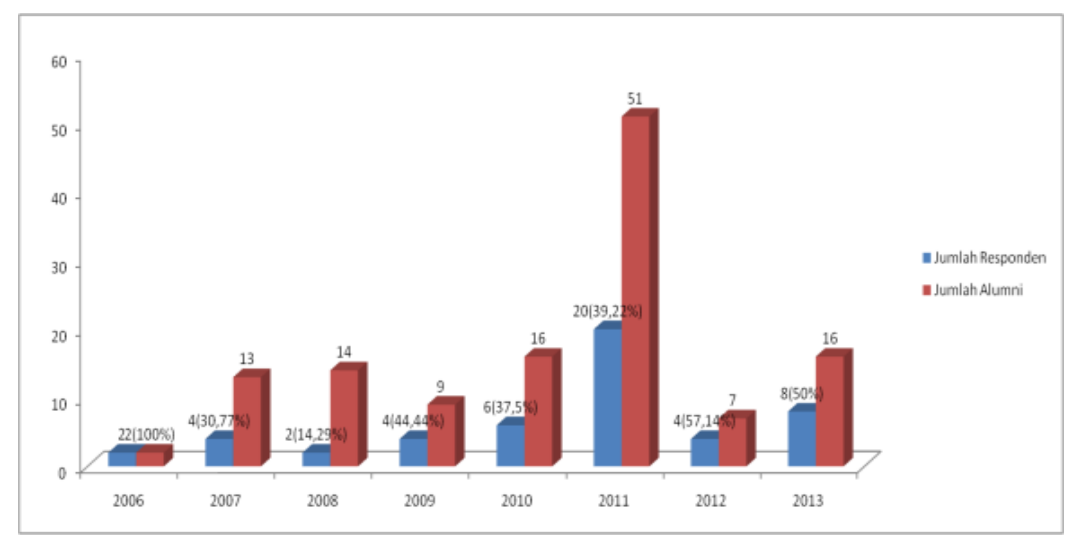

Gambar 1. Presentasi Partisipasi Responden terhadap Jumlah Lulusan Setiap Tahun

Berdasarkan gambar 1, dapat dilihat bahwa jumlah responden yang paling banyak berdasarkan tahun lulus terdapat di tahun 2011 dan yang berpartisipasi dalam pengis ian kuesioner yang terbanyak adalah responden yang lulus pada tahun 2011 yaitu sebanyak 20 responden atau $39,22 \%$ dari 51 responden. 


\subsection{Gambaran Umum Variabel}

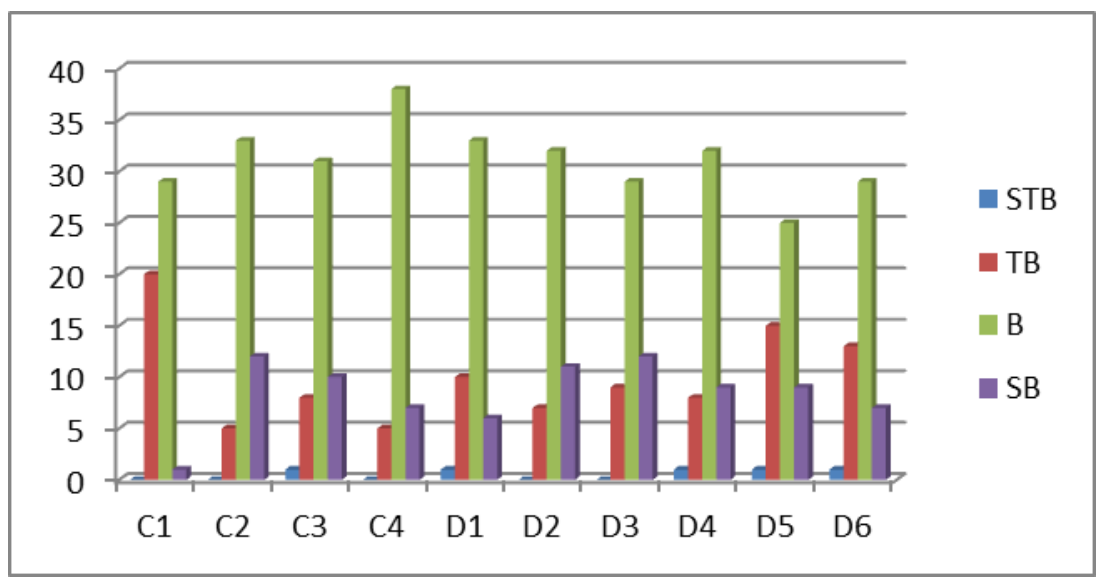

Gambar 2. Karakteristik Persepsi Responden Terhadap Setiap Kategori Kolom

Berdasarkan Gambar 2, secara umum alumni matematika menilai baik setiap kategori pada pelayanan yang ada di Jurusan Matematika FMIPA UNSRAT. Alumni menilai tidak baik untuk kategori karakteristik persepsi responden terhadap pemrograman matakuliah dengan fasilitas SIM, keterlibatan mahasiswa dalam riset ilmiah dosen, keterlibatan mahasiswa dalam pengabdian masyarakat dosen. Alumni yang menilai baik untuk kategori pemanfaatan teknologi untuk membantu penyelesaian pekerjaaan administrasi jurusan. Alumni menilai sangat baik untuk kategori kualitas publikasi dan riset ilmiah dosen.

\subsection{Analis is Korespondensi}

Dari hasil pengolahan data menggunakan program minitab 14 maka diperoleh hasil sebagai berikut.

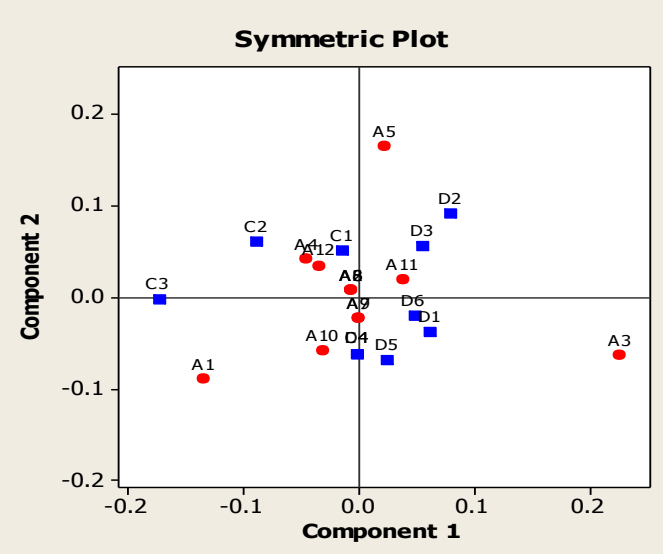

Gambar 3. Plot Korespondensi Alumni Lulusan Tahun 2006-2009

Pada Gambar 3, berdasarkan jarak antara satu alumni dengan alumni lainnya, dapat dilihat adanya hubungan satu sama lain yaitu A2, A6 dan A8, A4 dan A12, A7 dan A9, sedangkan alumni lainnya relatif berbeda. Berdasarkan jarak antara satu variabel dengan variabel lainnya, dapat dilihat adanya hubungan satu sama lain yaitu antara variabel D1 dan D6, variabel D2 dan D3, dan juga variabel D4 dan D5, sedangkan variabel lainnya relatif berbeda. Hubungan antara alumni dengan variabel layanan dan fasilitas akademik serta variabel publikasi ilmiah, riset dan pengabdian pada masyarakat yaitu, A4 dan A12 mempunyai kedekatan dengan variabel $\mathrm{C} 1$, dan A10 mempunyai kedekatan dengan variabel C4 dan D4, sedangkan yang relatif berjauhan terdapat pada variabel C3. Hasil analis is korespondensi untuk alumni lulusan 2006-2009 menunjukkan nilai 
kumulatif dari proporsi inersia dengan dimensi dua mempunyai nilai sebesar 63\%, hal ini menerangkan bahwa dua komponen utama pertama dapat menjelaskan $63 \%$ keragaman data.

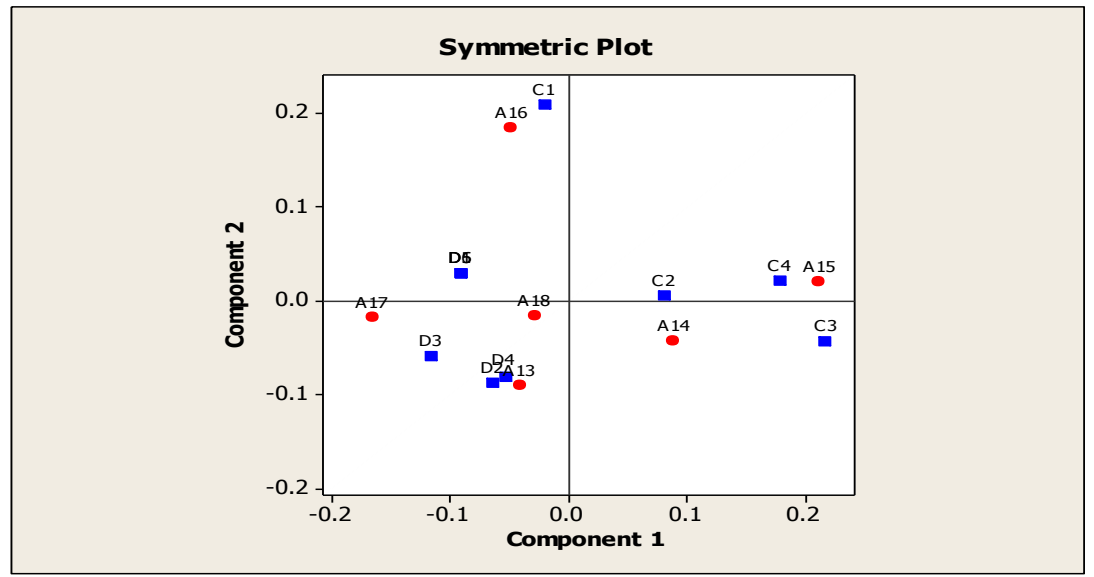

Gambar 4. Plot Korespondensi Alumni Lulusan Tahun 2010

Pada Gambar 4, berdasarkan jarak antara satu alumni dengan alumni lainnya, dapat dilihat bahwa hubungannya relatif berbeda. Berdasarkan jarak antara satu variabel dengan variabel lainnya, dapat dilihat adanya hubungan satu sama lain yaitu variabel D1, D5, dan D6, variabel D2 dan D4 sedangkan variabel lainnya relatif berbeda. Hubungan antara alumni dengan variabel yaitu, A13 memiliki kedekatan dengan variabel D2 dan D4, A15 memiliki kedekatan dengan variabel $\mathrm{C} 4$, A16 memiliki kedekatan dengan variabel $\mathrm{C} 1$. Hasil analisis korespondensi untuk alumni lulusan 2010 menunjukkan nilai kumulatif dari proporsi inersia dengan dimensi dua mempunyai nilai sebesar $71,2 \%$, hal ini menerangkan bahwa dua komponen utama pertama dapat menjelaskan $71,2 \%$ keragaman data.

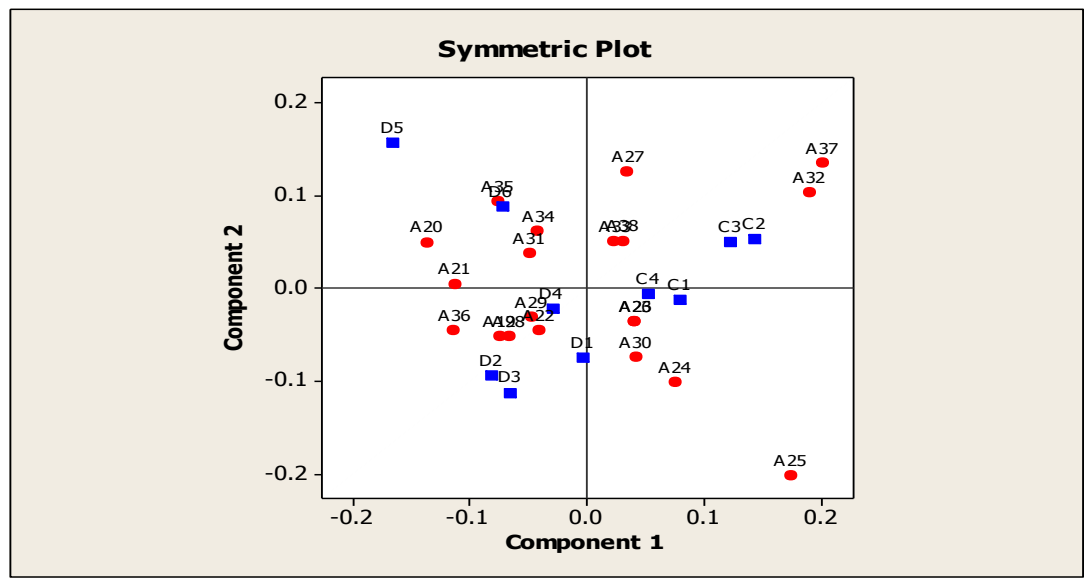

Gambar 5. Plot Korespondensi Alumni Lulusan Tahun 2011

Pada Gambar 5, berdasarkan jarak antara satu alumni dengan alumni lainnya, dapat dilihat adanya hubungan satu sama lain yaitu, A19 dan A28, A22 dan A29, A31 dan A34, A32 dan A37, A33 dan A38 sedangkan alumni yang relatif berbeda yaitu A25. Berdasarkan jarak antara satu variabel dengan variabel lainnya, dapat dilihat adanya hubungan satu sama lain yaitu antara variabel $\mathrm{C} 1$ dan $\mathrm{C} 4$, variabel $\mathrm{C} 2$ dan $\mathrm{C} 3$, variabel $\mathrm{D} 2$ dan D3 sedangkan variabel D5 relatif berbeda. Hubungan antara alumni dengan variabel yaitu, A26 memiliki kedekatan dengan variabel C4, A29 memiliki kedekatan dengan variabel D4, dan A35 memiliki kedekatan dengan variabel D6. Hasil analisis korespondensi untuk alumni lulusan 2011 menunjukkan nilai kumulatif dari 
proporsi inersia dengan dimensi dua mempunyai nilai sebesar $61,8 \%$, hal ini menerangkan bahwa dua komponen utama pertama dapat menjelaskan $61,8 \%$ keragaman data.

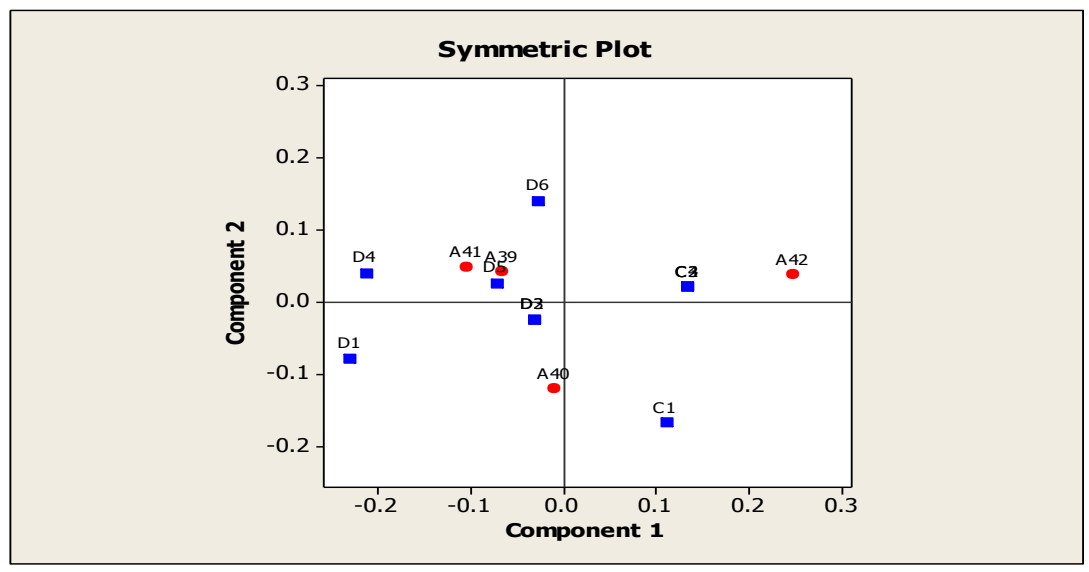

Gambar 6. Plot Korespondensi Alumni Lulusan Tahun 2012

Pada Gambar 6, berdasarkan jarak antara satu alumni dengan alumni lainnya, dapat dilihat adanya hubungan satu sama lain yaitu, A39 dan A41, sedangkan alumni lainnya relatif berbeda. Berdasarkan jarak antara satu variabel dengan variabel lainnya dapat dilihat adanya hubungan satu sama lain yaitu antara D2 dan D3 sedangkan variabel la innya relatif berbeda. Hubungan antara alumni dengan variabel yaitu A39 memiliki kedekatan dengan variabel D5. Hasil analisis korespondensi untuk alumni lulusan 2012 menunjukkan nilai kumulatif dari proporsi inersia dengan dimensi dua mempunyai nilai sebesar $86 \%$, hal ini menerangkan bahwa dua komponen utama pertama dapat menjelaskan $86 \%$ keragaman data.

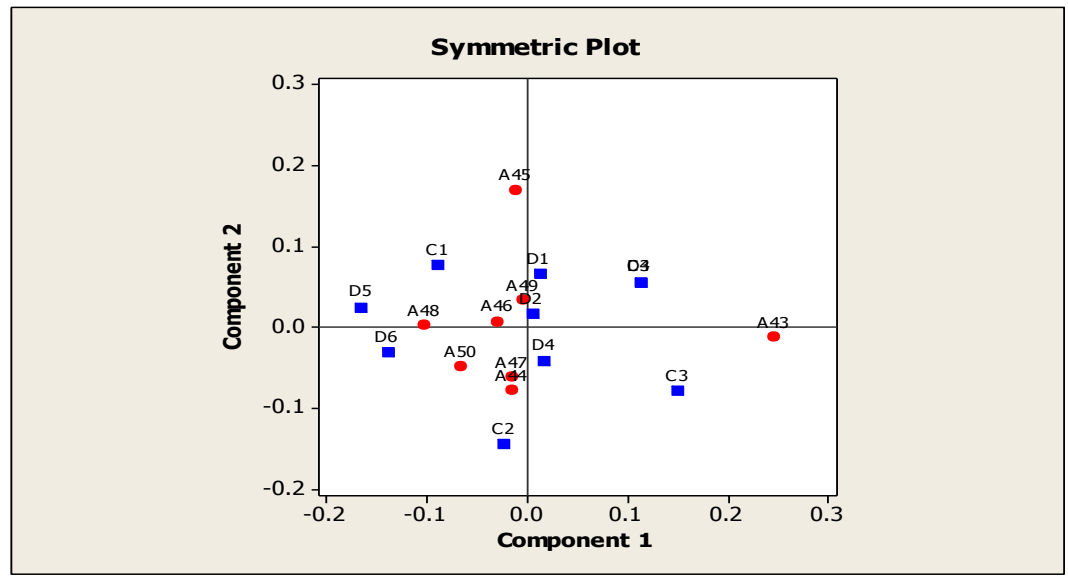

Gambar 7. Plot Korespondensi Alumni Lulusan Tahun 2013

Pada Gambar 7, berdasarkan jarak antara satu alumni dengan alumni lainnya, dapat dilihat adanya hubungan satu sama lain yaitu, A44 dan A47, dan A46 dan A49, sedangkan alumni la innya relatif berbeda. Berdasarkan jarak antara satu variabel dengan variabel la innya, dapat dilihat adanya hubungan satu sama lain yaitu antara D1 dan D2, sedangkan variabel lainnya relatif berbeda. Hubungan antara alumni dengan variabel yaitu, A46 dan A49 memiliki kedekatan dengan variabel D2, dan A47 memiliki kedekatan dengan variabel D4 sedangkan alumni dan variabel layanan dan fasilitas akademik serta publikasi ilmiah, riset, dan pengabdian pada masyarakat yang lain relatif berjauhan. Hasil analisis korespondensi untuk alumni lulusan 2012 menunjukkan nilai kumulatif dari proporsi inersia dengan dimensi dua mempunyai nilai sebesar 79,5\%, hal ini menerangkan bahwa dua komponen utama pertama dapat menjelaskan 79,5\% keragaman data. 


\section{Kesimpulan}

Dari hasil analisis korespondensi menunjukan bahwa ada kedekatan antara alumni dan variabel. Alumni 14, alumni 35, alumni 45, dan alumni 47 memberikan nilai sangat baik pada setiap variabel layanan dan publikasi ilmiah, sedangkan alumni 6 memberikan nilai yang kecil pada setiap variabel. Variabel pemanfaatan teknologi untuk membantu penyelesaian pekerjaan administrasi jurusan memiliki presentase paling banyak dinilai baik oleh alumni. Sedangkan untuk presentase paling banyak yang dinilai tidak baik oleh alumni yaitu pemrograman mata kuliah dengan fasilitas SIM. Secara umum alumni memberikan persepsi baik untuk setiap variabel layanan dan publikasi ilmiah.

\section{Daftar Pustaka}

[1] Grenacre, M.J. 1984. Theory and Applications of Correspondence Analysis. Academic Press Inc, London.

[2] Jean-Paul Benzécri, et al. 1973. Definition of Correspondence Analysis and Contingency Tables. Universite Pierre-et-Marie-Curie Paris, Perancis.

[3] Lebart, L., et all. 1984. Multivariate Descriptive Statistic Analysis Correspondence Analysis and Related Tecniques for Large Matrices. John Wiley and Sons Inc.

[4] Michael, J.G. 1984. Theory and Aplications of Correspondence Analysis. Academic Press. Inc.

[5] Rusgiyono, A. Analisis Korespondensi Untuk Pemetaan Persepsi. Jurnal Media Statistik. Vol 3(2):117-123. 2010. 